\title{
Hacia una literacidad crítica con enfoque de género en la enseñanza de literatura
}

\section{Towards a critical literacy with a gender approach in the teaching of literature}

DOI: https://doi.org/10.32870/dse.v0i23.965

\author{
Karla Michelle Canett Castro* \\ Laura Emilia Fierro López** \\ Lilia Martínez Lobatos***
}

\begin{abstract}
Resumen
En México, la literacidad se ha mostrado como una solución a los problemas de comprensión de lectura al darle a esta un enfoque sociocultural, a la vez que se fomenta el pensamiento crítico. El objetivo del presente texto es presentar los conceptos de literacidad crítica y de enfoque de género, así como los aspectos clave de la literacidad crítica de Vásquez (2017), para ampliarlas e incorporar un enfoque de género a partir de lo mencionado por Moreno (2000), Martínez-Martín (2016) y Martin et al., (2017). Desde esta perspectiva se discuten las 22 técnicas de literacidad crítica de Cassany (2006), la pedagogía de la literatura crítica (CLP) de Borsheim-Black et al. (2014), la pertinencia de ambas en la enseñanza de la literatura. Con todo lo anterior, se propone una serie de pautas para formular una literacidad crítica con enfoque de género, que se trabaje como un eje transversal en todas las asignaturas, ya que corresponde al eje de habilidades lectoras y de pensamiento crítico; esto quiere decir que tiene componentes actitudinales, y sobre todo sociales, que coadyuvan a la reflexión y análisis de las problemáticas de actualidad. Por otro lado, resulta difícil abordar esta perspectiva en las discusiones de clase sin el apoyo sólido del área de las ciencias sociales, donde se retomen contenidos declarativos necesarios para hacer un análisis sobre aspectos de poder, género, desigualdad, canon, norma, etc. Es decir, si bien es un eje transversal, es necesario contar con algunos conceptos claros para su aplicación.
\end{abstract}

Palabras clave: literacidad crítica - enfoque de género - enseñanza de literatura - estrategias de literacidad - ejes transversales.

\begin{abstract}
In Mexico, literacy has been shown as a solution to reading comprehension problems by giving it a sociocultural approach while promoting critical thinking. The aim of this text is to present the concepts of critical literacy and gender approach, as well as Vasquez' (2017) key aspects of critical literacy in order to expand
\end{abstract}

* Maestra en Lenguas Modernas. Líneas de investigación: Lingüística aplicada a la enseñanza y aprendizaje de lenguas, práctica educativa en lenguas. Facultad de Pedagogía e Innovación Educativa, Universidad Autónoma de Baja California. México. michelle.canett@uabc.edu.mx ** Doctora en Ciencias Educativas. Líneas de investigación: Lingüística aplicada a la enseñanza y aprendizaje de lenguas, práctica educativa en lenguas. Facultad de Idiomas, Universidad Autónoma de Baja California. México. laurafierro@uabc.edu.mx

*** Doctora en Ciencias Educativas. Líneas de investigación: Lingüística aplicada a la enseñanza y aprendizaje de lenguas, práctica educativa en lenguas. Facultad de Idiomas, Universidad Autónoma de Baja California. México. liliam@uabc.edu.mx 
them and incorporate a gender approach based on the contributions of Moreno (2000), Martínez-Martín (2016), and Martin et al. (2017). Based on this, Cassany's (2006) twenty-two critical literacy techniques and Borsheim-Black et al.'s (2014) Critical Literature Pedagogy (CLP) are discussed, as well as the relevance of both of them to the teaching of literature. We propose a series of guidelines to formulate a critical literacy with a gender approach that works across all academic subjects, since it corresponds to the axis of reading skills and critical thinking, which means that it has attitudinal and, above all, social components that contribute to reflect on and analyze current issues. On the other hand, it is difficult to address this perspective in class discussions without the solid support of the social sciences, where declarative knowledge is necessary to make an analysis on aspects of power, gender, inequality, canon, etc. That is, although it is a cross-cutting theme, it is necessary to have some clear concepts for its application.

Keywords: critical literacy - gender approach - literature teaching - literacy strategies - cross-cutting themes.

\section{Introducción}

En las últimas dos décadas, el término de literacidad ha tomado fuerza en el mundo de habla hispana, principalmente, a partir de los trabajos realizados por Cassany (2006). El término, una traducción literal del inglés Literacy-algunos autores como Kalman (2008) prefieren el de alfabetización; otros como Vargas (2018), el de cultura escrita-, se utiliza para nombrar a las prácticas de lectura y escritura, desde la alfabetización inicial hasta la lectura por medios digitales. En México, a nivel medio superior se promueven habilidades de lectura y escritura como eje transversal, aunque en la mayoría de los casos se trabajan dichas habilidades solo en las áreas de lengua y literatura. También, se mencionan temas sociales y ambientales de forma transversal. Estos ejes transversales pocas veces son abordados como tales $y$, en general, los docentes cuentan con pocas herramientas para incorporarlas en sus clases.

El presente trabajo busca discutir el concepto de literacidad crítica y sus aspectos clave para incluir también dentro de este una perspectiva de género que sirva para guiar todas las asignaturas. Por otro lado, se propone un modelo para trabajar el análisis de textos en las materias de Literatura de bachillerato de acuerdo a esta perspectiva. Es decir, una guía para fomentar una literacidad crítica con enfoque de género en las asignaturas de Literatura, que permita la discusión no solo de los aspectos básicos de teoría literaria, sino también de la interpretación de la obra y el canon.

\section{De qué hablamos cuando hablamos de literacidad crítica}

Los Nuevos Estudios sobre Literacidad (NEL) ubican la lectura más allá de una práctica individual y académica; la literacidad no solo ocurre en las mentes, es sobre todo una práctica social y cultural y debe ser estudiada como tal (Gee, 2015). En oposición a las concepciones cognitivas y psicológicas que estudian el individuo ligado a los procesos mentales de lectura y escritura, 
los NEL consideran que las prácticas responden a su contexto y que las personas no pueden prescindir de estas. Dentro de esta noción se enmarca la literacidad crítica.

La literacidad crítica es un término que engloba dos ámbitos: la literacidad, que es principalmente una práctica social y como tal abarca conocimientos, valores, actitudes, habilidades y todo aquello que nos permita interpretar un texto escrito; por otro lado, lo crítico, que se refiere a identificar posturas, ideologías y aquellas subjetividades que se encuentran en el texto. Es decir, corresponde a situar el escrito en su contexto sociocultural, identificar las prácticas discursivas que lo envuelven, así como los efectos que dicho discurso tiene en la comunidad y en uno mismo (Cassany, 2006). Por su parte, Luke (2004) lo define como una práctica social, cultural, pero, sobre todo, política. Aunque también hay autores como Vásquez (2014), que sitúan la literacidad crítica como un modo de vida, no solo como un aprendizaje académico.

Por lo tanto, se considera la literacidad crítica como una práctica social que consiste, primeramente, en interpretar un texto por medio de conocimientos, actitudes y valores considerando su situación sociocultural y sociopolítica para identificar la ideología e intenciones del autor detrás de este, incluso, aquellas subjetividades que van más allá del autor y que corresponden a estructuras de poder que pasan desapercibidas o se encuentran normalizadas en dichos ambientes. Pero, de igual forma, es un estilo de vida que permite interpretar el mundo -no solo textos- y apropiarse de textos y discursos para resignificarlos dentro de nuevas prácticas y contextos. Es decir, la literacidad crítica también como un agente de cambio social.

\section{Aspectos clave de la literacidad crítica}

Debido a la pluralidad de conceptos que se encuentran sobre literacidad crítica, Vásquez (2017) propone una serie de elementos a considerar para poder identificarla frente a otras literacidades y otras definiciones de lo crítico. A continuación, se presenta una traducción propia de los aspectos claves de la literacidad crítica que formula Vásquez (2017):

1. La literacidad crítica no es tema que debe ser cubierto dentro del currículo como tal, sino que debe ser visto como una perspectiva de enseñanza que se trabaja de forma transversal en las distintas asignaturas.

2. De acuerdo con lo anterior, el bagaje cultural, el conocimiento previo y sus diversas prácticas deben retomarse para construir el currículo. Esto debido a que el alumno aprende mejor cuando lo que se revisa en clase tiene relevancia en sus vidas.

3. Desde la literacidad crítica, el mundo es visto como un texto socialmente construido y, por lo tanto, puede ser leído. Entre más pronto se contagie a los alumnos con esta idea, más rápido podrán adoptar el rol de investigadores de su alrededor. Así como de las perspectivas e intenciones de los textos, pues nada es neutral. De esta forma ellos están conscientes de que todo puede reescribirse, replantearse. 
4. Los textos son socialmente construidos y creados desde perspectivas particulares, no son neutrales; pero tampoco las lecturas que hacemos de estos son neutrales. Cada vez que se lee un texto, se interpreta de acuerdo con el bagaje cultural, conocimientos previos y experiencias propias; por ello, también debemos cuestionar las lecturas que realizamos.

5. La literacidad crítica implica hacer conciencia sobre el sistema político en el que vivimos para poder cuestionarlo. Por lo tanto, el trabajo de la literacidad crítica debe enfocarse en temas sociales, como la raza, el género, clase social, discapacidades y el uso del lenguaje, que nos ayudan a moldearlos y entenderlos. Los discursos en estos temas influyen en cómo las personas son capaces de vivir o no su vida, ya que determinan a quién le damos poder en la sociedad.

6. Las prácticas de literacidad crítica pueden transformar y contribuir a cambiar la desigualdad de las problemáticas sociales. Los estudiantes que se involucran en estas prácticas desde los primeros años de escuela tienen mayores probabilidades de contribuir al desarrollo de una sociedad más equitativa y justa, debido a que tienen la capacidad de tomar decisiones considerando aspectos de control y poder.

7. El diseño y producción de un texto compete a la literacidad crítica, pues es durante este proceso que se toman decisiones que involucran perspectivas del autor. Es por ello que, si al alumno se le va a pedir producción de textos, estas deben trascender la práctica escolar y estar ligadas a temas sociales de actualidad.

8. Por último, la literacidad crítica consiste en imaginar formas bien pensadas y estructuradas para reconstruir y rediseñar textos, imágenes y prácticas que lleven a un mundo más justo y equitativo. Mensajes que tengan un impacto en la vida real y cotidiana.

Estos aspectos claves de Vásquez (2017) combinan lo social y pedagógico que envuelve a la literacidad crítica como una práctica social y un estilo de vida que trasciende el aula. Es importante resaltar que Vásquez menciona las cuestiones de control y poder, elementos primordiales para entender las desigualdades entre hombres y mujeres, y cómo estas se perpetúan mediante los planes y programas de estudio, así como en las dinámicas de clase. Como señala Vásquez, entre más rápido se haga consciente al alumno de estas situaciones y diferencias, más se involucra en las prácticas y cuestionamientos del sistema político imperante, el cual depende en gran medida de prácticas patriarcales.

También señala el componente transversal de la educación, es decir, no es solo una práctica social $-y$, por ende, una habilidad que tiene implicaciones culturales-, sino que, de igual forma, hay un componente actitudinal importante. Los ejes transversales son herramientas que contribuyen a la formación integral del alumnado, promueven la reflexión, la crítica, la empatía y la búsqueda de resolución de problemas sociales. Por ello, la literacidad crítica es un eje trans- 
versal de la educación, ya que dota al alumnado de actitudes y valores al promover la lectura y el pensamiento crítico, dos de los aspectos que se promueven en la educación media superior mediante las habilidades lectoras. Por lo tanto, no es un conocimiento declarativo que deba abordarse en una asignatura, sino permear todo el currículo y fomentarse en todas las asignaturas, es decir, trabajarse desde las distintas disciplinas.

Para lo anterior, Vásquez sugiere que los textos que se soliciten a los estudiantes trasciendan el aula y abarquen aspectos sociales de actualidad. Aunque, por otro lado, es importante no olvidar que, para lograr una producción de escritos que cuestionen el orden establecido, primero hay que aprender a diseccionar los textos a los que se enfrentan día a día los estudiantes, tanto expositivos (libros escolares, monografías, artículos, noticias) como de opinión (publicaciones en redes sociales, ensayos, columnas). Por ello, contar con estrategias de literacidad crítica resulta crucial para la práctica docente pues va más allá de solo leer y comentar, se deben observar y reflexionar sesgos e ideologías, así como silencios y posturas determinadas.

\section{Enfoque de género en la educación}

Los estudios de género y educación que surgieron en la década de los ochenta, buscaban evidenciar las diferencias latentes entre hombres y mujeres en el ámbito educativo (Buchmann, Edmunds, 2018). Lo anterior, desde una perspectiva más sociológica, pero que llevó a la reflexión de la práctica docente y así a la implementación de estrategias y propuestas para una educación con enfoque o perspectiva de género, educación no sexista, entre otros. La equidad de género es, al igual que la literacidad crítica, un eje transversal de la educación. Por lo tanto, es importante encontrar estrategias para promover este aspecto en todas las materias del currículum, desde preescolar hasta educación superior.

La perspectiva de género se entiende como "una categoría de análisis para el estudio de las construcciones culturales y sociales propias para los hombres y las mujeres, lo que identifica lo femenino y lo masculino" (Chávez, 2004: 10). Es decir, el género como una construcción social, cultural e histórica. El enfoque o perspectiva de género es una herramienta de análisis que identifica y discute las diferencias por razón de género y aboga por una educación sin distinciones ni estereotipos. Esto abarca desde los libros de texto, el material didáctico, hasta las lecturas y actividades que se promueven dentro y fuera del aula, ya que por estos medios se refuerzan estereotipos y desigualdades. Tal como lo menciona Moreno (2000), la escuela no solo se encarga de la formación intelectual de los individuos, también forma lo social y, con esto, lo ubica en las pautas culturales de la sociedad.

\section{Aspectos clave de una educación con enfoque de género}

Por lo anterior, los siguientes puntos son imprescindibles al momento de analizar un plan, programa o currículum con perspectiva de género. Muchos de los puntos que se mencionan a 
continuación tienen sus orígenes en la pedagogía feminista que surge a finales de la década de los ochenta. El enfoque de género, además de analizar las diferencias entre hombres y mujeres, también abarca los cuerpos disidentes, las distintas orientaciones sexuales, entre otros aspectos. A partir de esto, se proponen los siguientes puntos para trabajar con enfoque de género en el aula:

1. Uno de los aspectos principales es promover un intercambio constante entre maestro y alumno, y que este permita una reflexión crítica del contenido (Martin et al., 2017).

2. Por lo tanto, se debe examinar lo que se enseña y lo que no, a lo que se le da voz en el contexto educativo y aquello que se ignora dentro de este (Martin et al., 2017).

3. También, según el punto número uno, estas pedagogías visualizan a los docentes como aprendices, no como expertos que depositan conocimientos en los estudiantes (Conrad et al., 2011, como se citó en Martin et al., 2017).

4. El aprendizaje es y debe ser un proceso de transformación continua que dure toda la vida (Conrad et al., 2011, como se citó en Martin et al., 2017).

5. En una educación con enfoque de género se deben incorporar muchas voces y opiniones que enriquezcan cada asunto que se aborde en clase (Conrad et al., 2011, como se citó en Martin et al., 2017).

6. La educación debe retar, no reforzar normas ni injusticias sociales sin cuestionarlas (Conrad et al., 2011, como se citó en Martin et al., 2017).

7. Una educación con enfoque de género debe visibilizar, tomar conciencia y revisar nuestra posición dentro de la estructura, es decir, tomar conciencia de los propios privilegios (Martínez-Martín, 2016).

8. También, se deben analizar y deconstruir los diversos imaginarios patriarcales y sus mecanismos de normalización (Martínez-Martín, 2016).

Con lo anterior, se pueden encontrar puntos que coinciden con la literacidad crítica, sobre todo cuando se trata de cuestionar los cánones y el poder imperante. Ya lo identificaban también Ortega-Sánchez y Pagés (2017: 3) al decir:

Las vinculaciones de la literacidad con el tratamiento de las relaciones desiguales de género se relacionan, de forma directa, con la formación del pensamiento crítico, con el cuestionamiento de las fuentes de información y con la intencionalidad, voces y silencios de la información.

Es decir, la literacidad crítica y el enfoque de género son dos aspectos que van de la mano, no se puede promover una perspectiva de género en la educación sin abordar la literacidad crítica y, sobre todo, sin identificar las voces y los silencios de los textos. Tal como lo mencionaba 
Vásquez (2017), no hay texto neutral y se debe hacer consciente a los alumnos sobre esto. Por otro lado, Lee (1996) señala que la literacidad, concebida como una herramienta política, es de gran valor como categoría de análisis del feminismo, pues a través de las prácticas de lectura y escritura se reproducen discursos, que pueden ser analizados y discutidos por medio de prácticas de literacidad crítica en el aula.

De igual forma, es importante resaltar los primeros puntos que se retoman de Martin et al. (2017), donde se propone acotar la estructura de poder docente-alumno cuando el maestro es situado también como un aprendiz del proceso de enseñanza-aprendizaje. Esto resulta trascendental ya que son estas estructuras de dominación y poder las que refuerzan lo patriarcal. Al cuestionarlo, por medio de acciones que permitan el diálogo y el intercambio de saberes y experiencias, se escuchan otras voces y se refuerza la empatía. Si no hay espacio para ello, incluidas las mismas voces de los actores involucrados en el proceso de enseñanza como son los alumnos, resulta contradictorio hablar de literacidad crítica y enfoque de género. Es por ello que hablar de perspectiva de género en la educación es hablar e involucrar estrategias de literacidad crítica en el aula.

\section{Estrategias de literacidad crítica}

Desde principios de siglo, Cassany (2006) propone una serie de preguntas para cuestionar un texto e identificar las voces silenciadas y la ideología detrás de este. De igual forma, BorsheimBlack et al. (2014) enuncian cuestionamientos que permiten analizar textos literarios canónicos. A continuación, se presentan ambas propuestas para discutir su pertinencia dentro del programa de Literatura I y II de la Dirección General de Bachillerato (DGB) de la Secretaría de Educación Pública (2017).

\section{Veintidós preguntas de Cassany}

Cassany (2006) plantea una serie de recursos, en su mayoría preguntas y ejercicios, así como metáforas para fomentar la comprensión crítica. Divide las técnicas en tres grandes grupos: el primero, el mundo del autor, que incluye ocho técnicas; el segundo, el género discursivo, que también incluye ocho técnicas; por último, las interpretaciones del lector, donde incorpora seis técnicas. El mismo Cassany menciona que su propuesta es una guía, de ninguna manera una receta para el éxito. Recomienda que cada quien tome aquellas que le ayuden a desmenuzar los distintos textos.

Para el programa de Literatura de la DGB, lo que corresponde al mundo del autor es importante en el análisis del texto literario. Algunos puntos del género discursivo también podrían retomarse y, por supuesto, lo que corresponde a las interpretaciones. Aunque en un texto lírico este tipo de análisis se complica, en la narrativa, el género dramático y el ensayo literario son elementales. Si bien no es necesario hacer uso de todas las preguntas en todos los momentos, 
sí son una guía para el diálogo en clase o para pedir trabajos escritos a los alumnos. Por lo tanto, constituyen herramientas para iniciar discusiones que permitan cuestionar la norma, así como identificar ideologías y sesgos.

Sin embargo, esta propuesta de Cassany está más orientada a analizar textos de tipo persuasivo o expositivo y no enfatiza tanto los aspectos de género. Es decir, las veintidós técnicas de Cassany no son suficientes cuando se quieren analizar textos literarios; por otro lado, tampoco hace énfasis en las diferencias y desigualdades por razón de género. Las técnicas que propone Cassany resultan más convenientes para identificar ideologías políticas (derecha, centro, izquierda) y falacias argumentativas. Solo la técnica 6 hace referencia a si el autor es sexista, pero en general se percibe como una estrategia patriarcal para analizar los textos, ya que no proporciona herramientas suficientes para cuestionar el sexismo y la desigualdad de género, únicamente se pregunta si el autor lo es, mas no brinda otro tipo de cuestionamientos.

Debido a esto, tanto a la carencia de herramientas para discutir textos literarios como a la falta de preguntas para cuestionar el orden patriarcal en ellos, surgen otras propuestas para estudiar de forma crítica dichos textos. Esto sin olvidar que son literarios y que responden a otras características, pero que no por ello están exentos de ideologías, posturas y, por supuesto, de estereotipos sexistas y representaciones de abuso, violencia y desigualdad por razón de género.

\section{Pedagogía de la literatura crítica de Borsheim-Black, Macaluso y Petrone (2014)}

La necesidad de crear una propuesta que permitiera analizar los textos que se han vuelto canónicos en la educación secundaria en Estados Unidos, fue lo que motivó a estos autores a crear la Pedagogía de la Literatura Crítica (CLP por sus siglas en inglés). Conscientes de la importancia de incorporar los elementos de análisis tradicionales de los textos literarios, pero sin olvidar la parte crítica que vaya más allá del texto, ya que se trata de cuestionar los cánones, las voces silenciadas y las estructuras de poder.

El resultado es una pedagogía que permite trabajar con textos clásicos sin olvidar la mirada crítica. Borsheim-Black, Macaluso y Petrone (2014) mencionan que se puede leer con y contra el escrito, y para esto proponen una serie de preguntas divididas en cinco dimensiones: lo canónico, los contextos, los elementos literarios, el lector y la evaluación. La primera dimensión cuestiona la relevancia de la obra y del autor, así como lo que simboliza el canon y lo que hay detrás de este concepto; la segunda se enfoca en los contextos sociales, históricos, políticos, económicos y culturales en los que se produce la obra y, de igual forma, pregunta por aquellas otras historias que no están representadas en la obra y de cierta forma problematiza las verdades históricas que permean la literatura hasta nuestros días; la tercera se centra en los elementos literarios tales como personajes y símbolos, y las representaciones que se hacen en la obra -tanto de las minorías como de la cultura dominante- por medio de estos; la cuarta permite relacionar las experiencias y vivencias propias del lector con el texto y cuestionar sus propios privilegios;

Diólo os sobre Educación año 12 | número 23 | julio-diciembre 2021 | ISSN 2007-2171 
la quinta y última, evalúa el texto a partir de otras críticas e interpretaciones, sin olvidar lo ya analizado anteriormente en las otras dimensiones.

La CLP resulta una estrategia que, además de cuestionar estereotipos de género, también promueve la discusión de todas las voces minioritarias ausentes desde la perspectiva del feminismo interseccional, término acuñado por Crenshaw en 1989, pero particularmente conceptualizado a principios de los años 2000 por Collins (2002) y Hancock (2007). El término interseccional se refiere al análisis de las estructuras de poder relacionadas no solo con el género, sino también con la raza o la clase social. Es decir, la opresión se construye a partir de distintas categorías sociales a las cuales pertenece el individuo. La CLP se acerca a este perspectiva teórica, además de cuestionar el canon literario. A continuación se presenta la propuesta completa de la CLP. (véase tabla 1). 
Tabla 1. Preguntas para guiar la Pedagogía de la literatura crítica

\begin{tabular}{|c|c|c|c|}
\hline $\begin{array}{l}\text { Dimensión } \\
\text { de estudio } \\
\text { literario }\end{array}$ & Con & Contra & Ideas clave del CLP \\
\hline Canónico & $\begin{array}{l}\text { Considera el mérito del li- } \\
\text { bro. } \\
\text { ¿Qué es un/el canon? } \\
\text { ¿Qué obras son incluidas } \\
\text { en «el canon»? } \\
\text { ¿Qué tiene que decir la } \\
\text { crítica literaria sobre el } \\
\text { valor de esta obra/autor? } \\
\text { ¿Qué reconocimientos ha } \\
\text { recibido esta obra/autor? } \\
\text { ¿¿Por qué es importante } \\
\text { que leamos esta obra? }\end{array}$ & $\begin{array}{l}\text { Cuestiona la prominencia del texto. } \\
\text { ¿Cuáles son las consecuencias no } \\
\text { intencionadas de un/el canon? ¿Qué } \\
\text { refleja sobre los valores culturales? } \\
\text { ¿Qué debates rodean a este libro? } \\
\text { ¿Qué factores contribuyen a que } \\
\text { un texto se considere canónico? } \\
\text { ¿Quién decide qué es lo canónico? } \\
\text { ¿Qué otros textos escritos en el } \\
\text { mismo contexto histórico no son } \\
\text { incluidos en el currículo? } \\
\text { ¿Quién se beneficia o se marginali- } \\
\text { za con este libro? } \\
\text { ¿Deberías leer este libro? }\end{array}$ & $\begin{array}{l}\text { - Ningún texto es neutral. } \\
\text { - Las novelas canónicas -en vir- } \\
\text { tud de ser canónicas-refuerzan } \\
\text { valores culturales que deben } \\
\text { ser examinados y cuestionados. } \\
\text { - Los cánones literarios his- } \\
\text { tóricamente han privilegiado } \\
\text { ciertas voces y marginalizado } \\
\text { otras. } \\
\text { - Cómo leemos los libros, im- } \\
\text { portan tanto como cuáles libros } \\
\text { son enseñados. }\end{array}$ \\
\hline Contextos & $\begin{array}{l}\text { Identifica los contextos del } \\
\text { libro. } \\
\text { •QQué eventos o } \\
\text { movimientos históricos } \\
\text { importantes sucedieron } \\
\text { cuando este libro se escri- } \\
\text { bió? } \\
\text { ¿Cuáles son las «historias» } \\
\text { conocidas de este hecho } \\
\text { histórico? } \\
\text { ¿Cómo la novela refleja }\end{array}$ & $\begin{array}{l}\text { Identifica historias contrarias del } \\
\text { contexto del libro. } \\
\text { •¿Cómo este libro perpetúa y/o } \\
\text { subvierte entendimientos domi- } \\
\text { nantes de este contexto histórico? } \\
\text { ¿Qué versión de ese periodo } \\
\text { histórico cuenta el libro? } \\
\text { ¿Qué tan diferente sería la historia } \\
\text { si alguien de distinta raza, género o } \\
\text { procedencia étnica la escribiera? }\end{array}$ & $\begin{array}{l}\text { - Muchas de las novelas canóni- } \\
\text { cas refuerzan narrativas históri- } \\
\text { cas dominantes. } \\
\text { - Algunas novelas canónicas } \\
\text { rompen narrativas dominantes. } \\
\text { - Los cánones literarios típi- } \\
\text { camente han privilegiado las } \\
\text { voces de hombres y personas } \\
\text { blancas; las historias contrarias } \\
\text { pueden hacer visibles las ideo- } \\
\text { logías dominantes. }\end{array}$ \\
\hline
\end{tabular}
esas historias conocidas?

- ¿Cómo la novela refleja las experiencias de vida del autor?

Elementos Identifica elementos liteliterarios rarios.

- ¿Cuáles son los puntos centrales de la trama?

- ¿Cuáles son los símbolos principales del libro?

- ¿Cuáles son las consecuencias no

- Las novelas canónicas -en virvalores culturales que deben ser examinados y cuestionados. - Los cánones literarios históricamente han privilegiado ciertas voces y marginalizado

- Cómo leemos los libros, importan tanto como cuáles libros incluidos en el currículo?

za con este libro?

- ¿Deberías leer este libro? - ¿Cuáles los temas princi- o valorizada? ¿Se presenta como pales?

Considera los valores o ideologías que el texto reproduce.

- ¿Son los personajes de poblaciones históricamente marginadas o estereotipos?

- ¿La historia de quién es enfatizada víctima o héroe?

- ¿Cómo se desenvuelven • ¿Cómo la trama y temas apoyan los personajes?

o cuestionan las formas de pensar - ¿Cómolos elementos lite- tradicionales sobre los temas que rarios contribuyen al tema se plasman en el texto? •Cómo o universalidad del texto?

es que estos temas apoyan ciertos sistemas de creencias 0 ideas «normales» o universales?

- ¿Cómo es que los símbolos

Las novelas canónicas frecuentemente representan a las personas de grupos marginados de forma plana o simbólica. - Los personajes de grupos marginados frecuentemente interpretan un papel secundario en la trama de la novela, apoyando a un personaje principal o héroe de una cultura dominante.

- Los temas de las novelas canónicas frecuentemente refuerzan ideologías dominantes en temas de clase, orientación reflejan conocimientos culturales particulares? ¿Qué es lo que alguien debe saber para poder interpretar los símbolos usados? sexual, etcétera. 


\begin{tabular}{|c|c|c|c|}
\hline Lector & $\begin{array}{l}\text { Relaciona el texto con ex- } \\
\text { periencias personales. } \\
\text { - ¿Cómo relaciono a los } \\
\text { personajes o temas con mi } \\
\text { persona? } \\
\text { •¿Cómo mi (falta) conexión } \\
\text { moldea mi lectura de esta } \\
\text { novela? }\end{array}$ & $\begin{array}{l}\text { Considera perspectivas distintas a } \\
\text { la tuya o considera las propias de } \\
\text { una forma nueva que permita exa- } \\
\text { minar poder y privilegio. } \\
\text { ¿¿De qué forma mi identidad (se- } \\
\text { xualidad, edad, religión) moldea mi } \\
\text { lectura? } \\
\text { ¿Me relaciono más con los perso- } \\
\text { najes en el poder o con los margina- } \\
\text { dos? ¿Cómo este posicionamiento } \\
\text { afecta mi lectura del texto? }\end{array}$ & $\begin{array}{l}\text { - Solo relacionando puede mi- } \\
\text { nar intentos de comprometer } \\
\text { con el poder y la diferencia. } \\
\text { - Lectores de culturas domi- } \\
\text { nantes frecuentemente bata- } \\
\text { llan en identificar y cuestionar } \\
\text { ideologías dominantes porque } \\
\text { estas constantemente se man- } \\
\text { tienen invisibles a personas en } \\
\text { posiciones privilegiadas. }\end{array}$ \\
\hline Evaluación & $\begin{array}{l}\text { Análisis literarios estánda- } \\
\text { res. } \\
\text { •¿Qué análisis o críticas } \\
\text { literarias han sido escritas } \\
\text { sobre este libro? ¿Cómo } \\
\text { debería escribir mi } \\
\text { interpretación del texto en } \\
\text { relación con estas? } \\
\text { •Cómo debería escribir } \\
\text { una respuesta del lector, } \\
\text { una nueva crítica o nueva } \\
\text { interpretación histórica de } \\
\text { esta novela? }\end{array}$ & $\begin{array}{l}\text { Oportunidades para crear y distri- } \\
\text { buir textos que critican la norma } \\
\text { para audiencias reales. } \\
\text { ¿Cómo es que las ideas y la } \\
\text { información desarrollada en leer } \\
\text { con y contra los textos canónicos } \\
\text { es usada para informar, persuadir } \\
\text { a otros sobre opresión e injusticia, } \\
\text { particularmente en mi contexto? } \\
\text { ¿Cómo afectó el cambio basado en } \\
\text { mi aprendizaje crítico? }\end{array}$ & $\begin{array}{l}\text { - Relaciona entendimientos } \\
\text { críticos de temas en novelas ca- } \\
\text { nónicas con temas similares y } \\
\text { relevantes en otros contextos. } \\
\text { - Transfiere la literacidad críti- } \\
\text { ca usada para analizar novelas } \\
\text { canónicas a otro tipo de textos } \\
\text { (cultura popular, medios de co- } \\
\text { municación). }\end{array}$ \\
\hline
\end{tabular}

Fuente: Borsheim-Black, Macaluso y Petrone (2014). Traducción de Karla Michelle Canett Castro.

Como se puede apreciar, estas estrategias, al igual que las de Cassany (2006), permiten cuestionar y fomentar el pensamiento crítico. Sin embargo, las de Borsheim-Black et al. (2014) están orientadas específicamente a textos literarios, lo que permite mantener un análisis de los elementos de la teoría literaria, sin olvidar que también se trata de expresiones de la cultura de una época y, por lo tanto, también pueden ser analizados como tales. Además, las preguntas que plantea están orientadas a identificar voces silenciadas, privilegios de los lectores, prejuicios, estereotipos y, sobre todo, a cuestionar el canon y la norma, las estructuras de poder y de control que ejercen los grupos dominantes sobre grupos históricamente marginados y vulnerados, entre ellos, las mujeres. Es decir, no solo permiten trabajar de una forma más profunda las desigualdades por razón de género, sino también cuestionarlas, a diferencia de las técnicas de Cassany, que carecen de herramientas para cuestionar dichas estructuras. Si bien identificarlas y nombrarlas es importante, no es suficiente en la búsqueda de una equidad de género. La CLP permite ampliar la discusión y evidenciar directamente, no solo las desigualdades por razón de género, sino también de etnia, clase, lengua, edad y orientación sexual, lo que da una perspectiva amplia de las obras, así como de las representaciones culturales que hay en ellas.

Por lo expuesto anteriormente, se considera relevante el trabajo de Borsheim-Black et al. (2014) para el análisis de textos literarios, sobre todo con los canónicos, pues brinda más herramientas para trabajar los ejes transversales que involucren temas sociales, tales como las

Diólo@os sobre Educación 
desigualdes sociales y la equidad de género y que, como se mencionó, la propuesta de Cassany resulta deficiente en ese sentido. Además, el uso de textos literarios como herramienta para promover habilidades lectoras no es exclusivo de las materias de literatura, por lo que también permite ampliar su discusión en otras asignaturas.

\section{Hacia una literacidad crítica con enfoque de género}

Por lo expuesto anteriormente, una literacidad crítica con enfoque de género es una perspectiva de enseñanza que considera la lectura como una práctica social del lenguaje que cuestiona los textos sin ignorar el contexto social, cultural, económico y político que los envuelve, sobre todo, en aquellos aspectos que normalizan los sesgos de género y los imaginarios patriarcales. Por lo tanto, una educación que promueve la igualdad y el pensamiento crítico, así como la formación de ciudadanos responsables y comprometidos con su sociedad, deberá retomar los siguientes puntos que permiten fomentar una literacidad crítica con enfoque de género, los cuales surgen a partir de los aspectos clave, tanto de la literacidad crítica como del enfoque de género en la educación:

1. Esta es una perspectiva de enseñanza, no un tema más dentro del currículum, así que corresponde a un eje transversal que todas las asignaturas deben poner en práctica.

2. Para ello, deben considerarse los conocimientos previos de los alumnos, así como su bagaje cultural para relacionarlo con los contenidos nuevos.

3. Se debe tener claro que nada es neutral, ni el texto ni su lectura, y, debido a esto, todo puede rescribirse.

4. Una literacidad crítica con enfoque de género debe hacer conciencia del poder político y los propios privilegios para cuestionarlos, principalmente de aquellos relacionados con el género y sus mecanismos de normalización.

5. Los docentes deben solicitar producción de textos que estén ligados a temas sociales de actualidad.

6. En la planeación es importante incorporar distintas voces y opiniones sobre los contenidos que permitan identificar diversas posturas y perspectivas.

7. Por último, que exista un diálogo y discusión constante entre el docente y el alumno, así como de los textos y contenidos que se revisan y cuestionan en clase.

Si se trabaja a partir de lo expuesto, se aborda no solo con la literacidad crítica, sino que también se incorpora el enfoque de género. Los aspectos clave de ambos temas, combinados con las estrategias de literacidad crítica que proponen Cassany (2006) y Borsheim-Black et al. (2014), permiten analizar e incorporar una literacidad crítica con enfoque de género en las aulas, tanto de literatura como de otras asignaturas que se imparten en la educación media superior, de esta forma, se trabajen ejes transversales sociales como la equidad de género y las habilidades lectoras, a la par que se promueve un pensamiento crítico.

Diólo os sobre Educación año 12 | número 23 | julio-diciembre 2021 | ISSN 2007-2171 
Propuesta para trabajar una literacidad crítica con enfoque de género en literatura A continuación, se presenta un modelo para trabajar textos en las materias de Literatura de bachillerato acorde a los programas de estudio de la DGB. Se incorporan principalmente herramientas de la CLP y algunas de las veintidós técnicas de Cassany, así como aspectos de teoría literaria básica que se abordan en la asignatura. El modelo se divide en tres áreas: primera, una búsqueda previa a la lectura para contextualizar al alumno respecto a la obra, el autor y eventos sociohistóricos; segunda, aspectos estructurales de análisis de acuerdo al género literario; tercera, un apartado de discusión y reflexión respecto al texto, los contextos y el autor y el lector (véase la tabla 2). 
Tabla 2. Modelo de análisis de textos para la materia de Literatura

Antes de leer el texto, investiga los siguientes puntos:

\begin{tabular}{|c|c|c|}
\hline Sobre la obra & Sobre el autor & Sobre el contexto \\
\hline $\begin{array}{l}\text { • ¿Cuál es el género y subgénero de } \\
\text { la obra? } \\
\text { ¿En qué año se publicó? } \\
\text { ¿¿A qué corriente/época pertenece? } \\
\text { ¿¿Cuáles son las características de } \\
\text { dicha corriente? } \\
\text { ¿ ¿Se considera una obra importante } \\
\text { para la literatura? •Por qué? } \\
\text { ¿Qué dice la crítica sobre la obra? }\end{array}$ & $\begin{array}{l}\text { • ¿Quién es el autor? } \\
\text { •¿Es hombre, mujer, no binario, una persona } \\
\text { trans? } \\
\text { •¿Cuándo y dónde nació? } \\
\text { •¿Pertenece a algún grupo indígena? } \\
\text { • ¿Tiene estudios? ¿Cuáles fueron esos } \\
\text { estudios? } \\
\text { •¿Qué otras actividades realiza, además de } \\
\text { escribir? } \\
\text { •¿Ha ganado algún premio, beca o } \\
\text { reconocimiento por su trabajo creativo? } \\
\text { •¿Tiene familia (pareja, hijos)? } \\
\text { •¿Pertenece a alguna minoría ya sea por su } \\
\text { orientación sexual, su raza/etnia o religión? }\end{array}$ & $\begin{array}{l}\text { ¿QQué pasaba en el país de origen del au- } \\
\text { tor mientras se escribía la obra? } \\
\text { • ¿Había alguna guerra, conflicto armado, } \\
\text { movimiento social o político que haya } \\
\text { sucedido en esos años? } \\
\text { •¿Cuál era la situación política y } \\
\text { económica del país de origen del autor? } \\
\text { ¿¿Qué sucesos históricos marcaron esa } \\
\text { época? } \\
\text { • ¿En qué condiciones vivían los grupos } \\
\text { minoritarios en el país de origen del } \\
\text { autor durante esa época? } \\
\text { •¿Cuál era la situación de las mujeres } \\
\text { durante esa época? }\end{array}$ \\
\hline \multicolumn{3}{|c|}{ Una vez leída la obra, identifica los siguientes puntos de acuerdo al género literario: } \\
\hline $\begin{array}{l}\text { Narrativo: } \\
\text { - Tipo de narrador } \\
\text { - Lugares/espacios } \\
\text { - Tiempo } \\
\text { - Ambiente } \\
\text { - Personajes } \\
\text { - Trama } \\
\text { - Técnicas narrativas }\end{array}$ & $\begin{array}{l}\text { Lírico: } \\
\text { - Sujeto o hablante lírico } \\
\text { - Objeto lírico } \\
\text { - Recursos literarios }\end{array}$ & $\begin{array}{l}\text { Dramático: } \\
\text { - Personajes } \\
\text { - Trama } \\
\text { - Tiempo } \\
\text { - Actos, cuadros y escenas } \\
\text { - Acotaciones }\end{array}$ \\
\hline
\end{tabular}

Elabora un comentario del texto a partir de lo siguiente:

\begin{tabular}{|c|c|c|}
\hline Texto & Contextos y autor & Lector \\
\hline $\begin{array}{l}\text { - ¿Qué temas aborda la obra? ¿De } \\
\text { qué cosas habla? } \\
\text { •Qué características tiene los } \\
\text { personajes? ¿De qué sexo son? ¿A } \\
\text { qué clase social pertenecen? } \\
\text { • ¿Hay personajes femeninos? } \\
\text { ¿Representan algún estereotipo? } \\
\text { ¿Son protagonistas, secundarias, } \\
\text { ambientales? ¿Cuántos y qué hacen } \\
\text { dentro de la obra? ¿De qué forma } \\
\text { participan? ¿Cómo las describen? } \\
\text { - ¿Hay personajes de grupos } \\
\text { indígenas o racializados? ¿A qué } \\
\text { crees que se deba esto? } \\
\text { • ¿Hay personajes de minorías sexua- } \\
\text { les? ¿A qué crees que se deba esto? } \\
\text { • ¿Qué valores se perpetúan en la } \\
\text { obra? ¿De qué forma? }\end{array}$ & $\begin{array}{l}\text { •¿De qué manera refleja la obra el contexto, } \\
\text { la situación política, económica, histórica de } \\
\text { su tiempo? ¿De forma literal o utiliza otros } \\
\text { recursos? } \\
\text { •¿De qué manera refleja el autor su vida? } \\
\text { •Cómo se relaciona el contexto con los } \\
\text { temas que aborda la obra? } \\
\text { •Cómo este libro perpetúa y/o subvierte } \\
\text { entendimientos dominantes de este } \\
\text { contexto histórico? } \\
\text { •¿Qué versión de ese periodo histórico } \\
\text { cuenta el libro? } \\
\text { •QQué tan diferente sería la obra si alguien } \\
\text { de distinta raza, género o procedencia étnica } \\
\text { la escribiera? }\end{array}$ & $\begin{array}{l}\text { • ¿Te identificaste con algún personaje? } \\
\text { ¿Por qué? } \\
\text { •¿De qué forma se ven representados tus } \\
\text { privilegios en la obra? } \\
\text { • ¿Te relacionas más con los personajes } \\
\text { en el poder o con los marginados? } \\
\text { ¿Cómo este posicionamiento afecta tu } \\
\text { lectura del texto? } \\
\text { •Crees que el texto sería distinto si lo } \\
\text { hubiera escrito alguien de otro sexo? } \\
\text { ¿Por qué? ¿De qué forma? ¿Qué cambia- } \\
\text { ría? } \\
\text { • ¿Te provocó algo el texto? ¿Algún } \\
\text { sentimiento, emoción? ¿A qué crees que } \\
\text { se deba esto? }\end{array}$ \\
\hline
\end{tabular}

Fuente: elaboración propia.

Diólo os sobre Educación año 12 | número 23 | julio-diciembre 2021 | ISSN 2007-2171 
Con el presente modelo se cubre lo estipulado en los programas oficiales de la DGB, además de incorporar la literacidad crítica con enfoque de género al cuestionar la representación de las mujeres en la obra, pero sin dejar de lado la perspectiva interseccional que posee la CLP. De esta forma, tanto el alumno como el docente tienen una guía para la discusión. Si bien hay algunos conceptos propios de las ciencias sociales (privilegios, estructuras de poder, etc.), no hay que olvidar que los ejes transversales atraviesan todos los campos de conocimiento y que es imposible analizar las estructurales patriarcales sin cuestionar también al poder económico, político e histórico que intervienen en su construcción.

\section{Conclusiones}

Los ejes transversales de la educación son poco abordados tanto en la formación docente como en la planeación didáctica y su evaluación; sin embargo, constituyen uno de los elementos imprescindibles de la educación actual, lo que resulta en una gran paradoja: se exige que los estudiantes tengan una formación integral, que se cultiven en artes, ciencia, valores, pero los programas están llenos de contenidos que dejan un espacio mínimo para la reflexión y el análisis. Además, los indicadores y el seguimiento de los estudiantes solo se dan a partir de los conocimientos declarativos y procedimentales, dejando de lado los aspectos actitudinales. $Y$ es en esto último donde entra la literacidad crítica y el enfoque de género. Sin embargo, lo anterior no quiere decir que para trabajar y promover la literacidad crítica con enfoque de género no sean necesarios ciertos conocimientos; lo son, pero estos no deben abordarse en todas las asignaturas. Y es aquí donde la interdisciplina y la transversalidad se cruzan. Para poder discutir y analizar textos literarios a partir de la propuesta de Borsheim-Black et al. (2014), el estudiante debe conocer ciertos conceptos: privilegio, canon, norma, raza, clase social, etnia, discriminación, estructuras de poder, entre otros. Estos no son contenidos propios del área de humanidades, donde se enmarca la materia de Literatura, pero sí son necesarios para poder guiar la discusión en clase a partir de la obra y los textos literarios. Se puede lograr una reflexión desde las experiencias de los estudiantes, no obstante, nombrar y conceptualizar esas diferencias e injusticias brinda una claridad a las violencias y abusos que atraviesan las obras, así también como a su persona.

Es aquí donde las materias del área de Ciencias Sociales resultan fundamentales para trabajar los ejes transversales, sobre todo los que corresponden al aspecto social. En este texto se presentan algunos puntos a considerar para el diseño de estrategias que promuevan una literacidad crítica con enfoque de género en las materias de literatura, un apoyo para que el docente pueda generar una discusión en clase y guiar a los estudiantes en sus procesos de reflexión. Aunque no hay que olvidar que cada asignatura debe aportar desde su disciplina al análisis y el fomento de los ejes transversales, así como de otros aspectos actitudinales, ya sea con gestos menos directos que los que propone la CLP (como nivelar la participación en clase entre hombres y mujeres, promover la lectura de autoras, entre otras), como con cuestionamientos directos y discusiones en torno a temas de actualidad. 
Erradicar las violencias y las brechas por razón de género, no es un trabajo exclusivo del sector educativo, pero sí es un espacio con un fuerte impacto en la vida de las personas. Sin embargo, aunque en los planes y programas se mencionan como temas importantes a abordar, la falta de formación y actualización docente convierten a la literacidad crítica y a la equidad de género en ejes relegados en los proyectos de enseñanza y en la práctica educativa.

\section{Referencias}

Borsheim-Black, C.; M. Macaluso; R. Petrone (2014). Critical Literature Pedagogy: Teaching Canonical Literature for Critical Literacy. Journal of Adolescent \& Adult Literacy, 58(2), 123-133. https://www.jstor.org/stable/24034704

Buchmann, C.; Ch. Edmunds (2018). Gender and Education. En Spillman, L. (ed.). Oxford Bibliographies in Sociology. Nueva York: Oxford University Press. https//doi.org/10.1093/OBO/9780199756384-0151

Chávez, J. (2004). Perspectiva de género. México: Plaza y Valdés.

Cassany, D. (2006). Tras las líneas: sobre la lectura contemporánea. Barcelona: Anagrama.

Collins, P. H. (2002). Black Feminist Thought: Knowledge, Consciousness, and the Politics of Empowerment. Nueva York: Routledge Taylor \& Francis Group.

Gee, J. (2015). The New Literacy Studies. En Rowsell, J.; K. Pahl (eds.). The Routledge Handbook of Literacy Studies. Londres: Routledge, 35-48. https://doi.org/10.4324/9781315717647

Hancock, A. M. (2007). Intersectionality as a Normative and Empirical Paradigm. Politics \& Gender, 3(2), 248.

Kalman, J. (2008). Discusiones conceptuales en el campo de la cultura escrita. Revista lberoamericana de Educación, 46(2008), 107-134. https://rieoei.org/historico/documentos/rie46a06.pdf Lee, A. (1996). Gender, Literacy, and Curriculum. Londres: Routledge Taylor \& Francis Group. Luke, A. (2004).Two Takes on the Critical.En Norton, B.; K. Toohey (eds.). Critical Pedagogies and Language Learning. Cambridge University Press, 21-29. https://doi.org/10.1017/CBO9781139524834.002

Martin, J.; A. Nickels; M. Sharp-Grier (2017). Feminist Pedagogy, Practice, and Activism: Improving Lifes for Girls and Woman. Londres: Routledge Taylor \& Francis Group.

Martínez-Martín, I. (2016). Construcción de una pedagogía feminista. Foro de Educación, 14(20), 129-151. http://dx.doi.org/10.14516/fde.2016.014.020.008

Moreno, M. (2000). Cómo se enseña a ser niña: el sexismo en la escuela. España: Icaria.

Ortega-Sánchez, D.; J. Pagés (2017). Literacidad crítica, invisibilidad social y género en la formación del profesorado de Educación Primaria. Revista de Investigación en Didáctica de las Ciencias Sociales, (1), 102-117. https://doi.org/10.17398/2531-0968.01.118 
Secretaría de Educación Pública (2017). Programa de estudios: Literatura I. Dirección General de Bachillerato.

https:/www.dgb.sep.gob.mx/informacion-academica/programas-de-estudio/3erSEMESTRE/Literatural.pdf

Vargas, A. (2018). Nuevos estudios de cultura escrita y educación: implicaciones para la enseñanza del lenguaje en Colombia. Perspectiva Educacional, 57(3), 153-174.

Vásquez, V. (2014). Re-desingning Critical Literacies. En Zacher, J.; J. Ávila, Moving Critical Literacies Forward: A Mew Look at Praxis across Contexts. Londres: Routledge, 175-186. https:// goo.gl/zUkxid

Vásquez, V. (2017). Critical Literacy. Oxford Research Encyclopedia of Education. http:// education.oxfordre.com/view/10.1093/acrefore/9780190264093.001.0001/acrefore-9780190264093-e-20 